\title{
Estandarización de la técnica de PCR-RFLP de la región ITS1, para la caracterización molecular de Leishmania (L.) infantum, en muestras caninas
}

Enmanuel Céspedes Chaves ${ }^{\mathrm{I}}$, Nilda Portillo ${ }^{\mathrm{I}}$, Vanette Thomaz-Soccol ${ }^{\mathrm{II}}$, André Luiz Gonçalves ${ }^{\mathrm{II}}$, Nilsa González Brítez ${ }^{\mathrm{I}}$

I Departamento de Medicina Tropical. Instituto de Investigaciones en Ciencias de la Salud - Universidad Nacional de Asunción, Paraguay.

II Laboratorio de Biología Molecular del Programa de Post-graduación en Ingeniería de Bioprocesos y Biotecnología de la Universidad Federal del Paraná, Brasil.

Cómo referenciar este artículo/ How to reference this article:
Céspedes Chaves E, Portillo N, Thomaz-Soccol V, Gonçalves AL, González Brítez N. Estandarización de la técnica de PCR-RFLP de la región ITS1, para la caracterización molecular de Leishmania (L.) infantum, en muestras caninas. Mem. Inst. Investig. Cienc. Salud. 2016;14(3):24-33

\section{RE S U M E N}

La leishmaniasis es una enfermedad producida por protozoarios parásitos del género Leishmania. Estos parásitos infectan a hospedadores mamíferos, entre los cuales los perros han sido implicados como reservorios del parásito. Este trabajo planteó estandarizar la técnica de la PCR-RFLP luego de la amplificación de la región ITS1 de Leishmania spp, como herramienta útil para la detección y caracterización molecular. Se utilizaron promastigotes de cultivo y muestras de biopsias procedentes de perros con leishmaniasis visceral previamente diagnosticados en el Centro Antirrábico Nacional. La región ITS1 del ADN genómico nuclear de Leishmania spp. fue amplificada utilizando los cebadores LITSR y L5,8S. La técnica ITS1 PCR-RFLP aplicada, permitió la detección de Leishmania (Leishmania) infantum en 10/10 aislados de parásitos mantenidos en medio NNN, en 10/18 muestras de bazo y 10/18 muestras de ganglio linfático poplíteo. Las condiciones óptimas de reacción fueron $0,2 \mathrm{mM}$ de dNTPs, $0,1 \mathrm{pmol}$ de cada cebador y $1 U$ de Taq polimerasa. La sensibilidad de la PCR fue de $3 \mathrm{ng} / \mu \mathrm{L}$ de ADN en aislados de cultivo NNN y $60 \mathrm{ng} / \mu \mathrm{L}$ de ADN en muestras de biopsias, mientras que la especificidad fue de $100 \%$ para la detección de Leishmania sp. La enzima de restricción Hae III, determinó fragmentos de 184, 72 y 55 pb., que resultaron específicos para la especie Leishmania (L.) infantum. El marcador utilizado resultó confiable para la detección y caracterización de Leishmania sp. en perros procedentes de zonas endémicas, lo cual podría ser útil para verificar las especies de parásitos circulantes entre los perros.

Palabras claves: Leishmania infantum, perros, ITS -1 (Espaciador transcripto interno 1).

\section{Standardization of PCR-RFLP technique of the ITS-1 region for Leishmania (L.) infantum molecular characterization in canine samples}

\section{A B S T R A C T}

Leishmaniasis is a disease caused by protozoan parasites of the genus Leishmania. These parasites infect to mammalian hosts, including canines that have been implicated as reservoirs of the parasite. The aim of this research was to standardize the technique of PCRRFLP after amplification of the ITS1 region of Leishmania (Leishmania) infantum, as a useful tool for detection and molecular characterization. Promastigotes from culture and biopsies from dogs with visceral Leishmaniasis previously diagnosed by the Centro Antirrábico Nacional. The ITS1 region of the genomic DNA of Leishmania sp. was amplified using LITSR and L5,8S primers. The technique ITS1 PCR-RFLP applied, allowed the detection of 
Leishmania (L.) infantum in 10/10 of the isolates from parasites maintained in NNN culture medium, in 10/18 samples from spleen and 10/18 samples from popliteal lymph node. Optimal reaction conditions were $0.2 \mathrm{mM}$ dNTPs, 0.1 pmol of each primer and $1 \mathrm{U}$ of Taq polymerase. The sensitivity of PCR was $3 \mathrm{ng} / \mu \mathrm{L}$ DNA in isolates of parasites from NNN culture medium and $60 \mathrm{ng} / \mu \mathrm{L}$ DNA in biopsy samples while the specificity was $100 \%$ for the detection of DNA of Leishmania sp. The restriction enzyme Hae III determined fragments of 184, 72 and 55 bp., which were specific to Leishmania (L.) infantum. The marker used is reliable for the detection and characterization of Leishmania sp. in dogs from endemic areas, which could be useful to verify the species of parasites circulating among animals.

Keywords: Leishmania infantum, dogs, ITS1 (Internal Transcribed Spacer 1).

\section{INTRODUCCIÓN}

La leishmaniasis se define como una histoparasitosis producida por protozoos parásitos del género Leishmania, de localización intracelular (macrófagos), caracterizada por diversas manifestaciones clínicas y transmitidas por la picadura de insectos del género Lutzomyia en el nuevo mundo (1). Afecta a mamíferos entre los que se incluye el hombre. Clínicamente los cuadros pueden variar desde lesiones cutáneas ulcerosas que cicatrizan; leishmaniasis cutánea (LC), las no ulcerosas o difusas que no curan fácilmente; leishmaniasis cutáneo difusa (LCD), la forma mucosa llamada leishmaniasis mucocutánea (LMC) y la forma sistémica fatal Ilamada leishmaniasis visceral (LV). Las manifestaciones clínicas dependen tanto del estado inmunológico del hospedador como de la especie causante de la infección, con al menos 20 especies patógenas para el humano $(2,3)$. La leishmaniasis es considerada como un importante problema de salud pública, debido al aumento en el número de casos. El riesgo de infección parasitaria se asocia no sólo con factores ambientales tales como migraciones masivas, urbanización, deforestación; sino también se encuentran factores individuales como infección con VIH, desnutrición, genética, entre otros (3). Los perros domésticos han sido implicados como reservorios del parásito, pudiendo ser asintomáticos o sufrir la enfermedad, dependiendo de la respuesta inmunológica del animal (4).

De esta forma, la leishmaniasis visceral canina (LVC) está ampliamente distribuida en América del Sur y es una de las enfermedades caninas más importantes de la región, principalmente debido a su importancia zoonótica (5). Varias especies de parásitos de Leishmania sp. han sido aislados de perros en América del Sur y caracterizados molecularmente, entre estos se incluyen Leishmania braziliensis, L. peruviana, L. colombiensis, L. mexicana, L. panamensis, L. guyanensis, L. amazonensis, L. pifanoi y L. infantum $(5,6)$. Diversos métodos de caracterización se han aplicado para el estudio de este género, tales como electroforesis de isoenzimas, análisis del ADN del kinetoplasto (ADNk), la técnica de ADN polimórfico amplificado al azar (RAPD) y la tipificación molecular (7-11). En los últimos años, la reacción en cadena de la polimerasa, seguida del análisis de la longitud de los fragmentos de restricción del producto amplificado (PCR-RFLP), se ha erigido en una importante herramienta, no solo para la identificación, sino para la caracterización de especies de este género, en distintas zonas geográficas $(12,13)$. Es así que la identificación y caracterización precisa de las especies de Leishmania sp. es importante y necesaria para conocer sus características epidemiológicas, así como para documentar su distribución, lograr nuevos esquemas de tratamiento y finalmente lograr el diseño de medidas de control apropiadas a cada región $(14,15)$. Tomando en cuenta los antecedentes mencionados, este trabajo tuvo como objetivo, optimizar las condiciones de la PCR-RFLP/ITS1, utilizando ADN de aislados de parásitos en medio de cultivo bifásico NNN y muestras de biopsias (bazo y ganglio linfático poplíteo) obtenidas de perros con diagnóstico serológico positivo para la leishmaniasis visceral.

\section{MATERIALES Y MÉTODOS}

Muestras: Se utilizaron 10 aislados obtenidos previamente en cultivos de promastigotes de la siembra del bazo y 36 muestras biológicas de perros con diagnóstico clínico y serológico positivo para la LV. Fueron seleccionados animales procedentes del Departamento Central, destinados a eutanasia humanitaria a cargo del Programa Nacional de Control de Zoonosis y Centro Antirrábico Nacional (PNCZ y CAN), dependiente del Ministerio de Salud Pública y Bienestar Social, previo consentimiento de los dueños. Las muestras fueron colectadas durante el periodo de marzo a agosto del 2015. A cada animal 
se le extrajo una porción del bazo, y del ganglio linfático poplíteo. Una porción de cada muestra del bazo fue sometida a cultivo en medio bifásico NNN. Las cepas utilizadas como controles positivos fueron mantenidas en el mismo medio de cultivo durante las pruebas realizadas, para lo cual se utilizaron cepas de referencia internacional de tres especies del género Leishmania, tales como Leishmania (Leishmania) infantum (MHOM/FR/78/LEM75), Leishmania (Viannia) braziliensis (MHOM/BR/75/M2903), Leishmania (Leishmania) amazonensis (MHOM/BR/73/M2269), las cuales fueron proveídas por el Laboratorio de Biología Molecular del Programa de Post-graduación en Ingeniería de Bioprocesos y Biotecnología de la Universidad Federal del Paraná, Brasil.

Cultivo in vitro de Leishmania: Pequeñas porciones del bazo (aproximadamente 2-3 $\mathrm{mm}^{2}$ ) fueron sometidas a lavado con buffer salino fosfato (PBS $1 X$ ) esterilizado, $\mathrm{pH} \mathrm{7,2,} \mathrm{con}$ el fin de aislar promastigotes en medio de cultivo bifásico NNN suplementado con medio Schneider (Sigma, EEUU), gentamicina, estreptomicina $200 \mu \mathrm{g} / \mathrm{mL}$ y suero fetal bovino al $10 \%$ inactivado por calor (16). Los cultivos fueron mantenidos en incubadoras a $26^{\circ} \mathrm{C}$. El crecimiento exponencial de los parásitos fue el parámetro obligado para la extracción de ADN y fueron descartados aquellos medios que demostraron algún tipo de modificación durante el procedimiento. En forma paralela, restos del órgano y ganglio linfático poplíteo fueron conservados a $-20{ }^{\circ} \mathrm{C}$ hasta su posterior extracción de ADN.

Extracción de ADN: La extracción de ADN de los aislados se realizó por el método convencional (fenol-cloroformo) tomando como referencia la propuesta de Sambrook J, et al (17) y de Meredith SEO, et al (18). Se procedió a la extracción a partir de la fase líquida del medio de cultivo que contenía las formas promastigotes. Las muestras fueron sometidas previamente a lisis celular y digestión de ARN mediante un buffer de lisis (10 mM de Tris, $10 \%$ SDS $\mathrm{p} / \mathrm{v}$ a concentración final de $0,5 \%$ y ARNasa a concentración final de $100 \mu \mathrm{g} / \mathrm{mL}$ ) a $37^{\circ} \mathrm{C}$ por $30 \mathrm{~min}$. , posteriormente la digestión de proteínas se realizó con proteinasa $\mathrm{K}$ mediante incubación a $60{ }^{\circ} \mathrm{C}$ por toda la noche. La eliminación de proteínas y los procesos de precipitación, lavado y resuspensión, se realizó según el protocolo ya mencionado. Por otra parte, las muestras de biopsia de los órganos mantenidos a $-20{ }^{\circ} \mathrm{C}$, fueron descongeladas y lavadas con buffer salino fosfato (PBS 1X) esterilizado, $\mathrm{pH} \mathrm{7,2} \mathrm{y} \mathrm{maceradas}$ para la extracción de ADN mediante el Kit comercial Wizard ${ }^{\circledR}$ Genomic DNA Purification kit (PROMEGA, EEUU), siguiendo el protocolo recomendado por el fabricante.

Cuantificación de ADN: La concentración y pureza del ADN extraído se estimó midiendo la absorbancia a $260 / 280 \mathrm{~nm}$. Este procedimiento se realizó en un cuantificador de ADN/ARN/PROTEÍNA (NanoVue ${ }^{\mathrm{TM}}$ Plus Spectrophotometer, RU). El grado de pureza se calculó dividiendo la absorbancia a $260 \mathrm{~nm}$ entre la absorbancia a $280 \mathrm{~nm}$. Valores óptimos de pureza se encuentran entre 1,7-1,9 (19).

Reacción en cadena de la polimerasa (PCR): Con el fin de obtener fragmentos correspondientes al ADN de la región ITS1 de Leishmania sp., se optimizaron las condiciones de la reacción en un volumen final de $25 \mu \mathrm{L}$ mediante la variación de la concentración de determinados componentes. Se utilizaron los cebadores: LITSR: 5'-CTGGATCATTTTCCGATG-3' (directo) y L5,85: 5'-TGATACCACTTATCGCACTT-3' (reverso), ya reportados por Schönian et al (20) y Kuhls et al (21), que amplifican una región de 300 a $350 \mathrm{pb}$. denominada ITS1 que se encuentra entre los genes SSU rRNA y 5,8S rRNA del género Leishmania. La longitud del amplicón obtenido depende de la especie del género Leishmania que haya sido aislado. La mezcla de reacción para la amplificación contenía Buffer $1 \mathrm{X}, 1,5 \mathrm{mM}$ de $\mathrm{MgCl}_{2}, 1 \mu \mathrm{g} / \mu \mathrm{L}$ de BSA (Sigma, EEUU), 0,2 mM de dNTPs (dATP, dTTP, dCTP y dGTP), 0,1 pmol de cada cebador, $1 \mathrm{U}$ de Taq polimerasa, y agua destilada libre de ADNasa/ARNasa UltraPure ${ }^{\mathrm{TM}}$ (Invitrogen, EEUU). Para la amplificación de muestras de cultivos se requirieron $3 \mathrm{ng} / \mu \mathrm{L}$ de ADN molde. La amplificación a partir de muestras de biopsia solo fue posible a partir de $60 \mathrm{ng} / \mu \mathrm{L}$ del ADN molde. En todos los casos, se utilizó un control negativo que contenía todos los componentes de la mezcla de reacción, excepto el ADN molde, el cual fue sustituido por agua libre de ADNasa/ARNasa UltraPure ${ }^{T M}$ (Invitrogen, EEUU).

La amplificación se realizó en un termociclador de ADN (Veriti ${ }^{\circledR}$ Thermal Cycler, EEUU), siguiendo las modificaciones propuestas por el Laboratorio de Biología Molecular de la Universidad Federal del Paraná y tomando como referencia la propuesta de Schönian et al (20) y Kuhls et al (21). Las condiciones de tiempo y temperatura utilizadas fueron desnaturalización inicial a $94^{\circ} \mathrm{C}$ por 2 min, seguida de 40 ciclos de procesos de desnaturalización $\left(94^{\circ} \mathrm{C}\right.$ por $\left.30 \mathrm{~s}\right)$, hibridación $\left(53^{\circ} \mathrm{C}\right.$ por $\left.30 \mathrm{~s}\right)$ y extensión $\left(72^{\circ} \mathrm{C}\right.$ por $\left.30 \mathrm{~s}\right)$. Finalmente, un último proceso de extensión se realizó a $72^{\circ} \mathrm{C}$ por $10 \mathrm{~min}$.

Mem. Inst. Investig. Cienc. Salud. 2016;14(3):24-33 
Análisis de los productos de amplificación: Los amplicones fueron visualizados por electroforesis en gel de agarosa al 1\%, en buffer TBE 1X (45 mM Tris - borato, 1 mM EDTA) tanto para la fase móvil como para la fase estacionaria, se utilizaron cubas horizontales, y los geles fueron corridos a 75 Volts durante $40 \mathrm{~min}$. Para la verificación del tamaño de los amplicones, se utilizó un marcador de tamaño molecular en escalera de $1 \mathrm{~Kb}$ (Invitrogen, EEUU), el gel fue visualizado bajo luz UV, previa tinción con Bromuro de etidio $(0,5 \mu \mathrm{g} / \mathrm{mL})$ por 20 min. y un lavado en agua destilada por $10 \mathrm{~min}$. El resultado final de la electroforesis se fotodocumentó mediante la captura de imágenes en alta resolución bajo luz ultravioleta (UV) utilizando el transiluminador L-PIX TOUCH (LOCCUS Biotecnología, BR).

Digestión enzimática de los amplicones: La restricción de los productos de PCR se realizó con la enzima Hae III (Invitrogen, EEUU) siguiendo las instrucciones del fabricante. La mezcla contenía agua ultra pura, Buffer M 10X, la enzima de restricción Hae III (10 U/ $\mathrm{LL})$ y finalmente el producto de PCR. La mezcla fue incubada a $37^{\circ} \mathrm{C}$ durante toda la noche. Los perfiles de bandas fueron identificados por electroforesis en gel de agarosa al 3\%, utilizando tampón TBE 1X. Para la verificación de la longitud de los productos de la digestión se utilizó un marcador de tamaño molecular en escalera de $50 \mathrm{pb}$ (Invitrogen, EEUU), el gel fue visualizado bajo luz UV, previa tinción con Bromuro de etidio $(0,5 \mu \mathrm{g} / \mathrm{mL})$ por $20 \mathrm{~min}$. Se realizó la captura de imágenes en alta resolución bajo luz ultravioleta (UV) utilizando un transiluminador L-PIX TOUCH (LOCCUS Biotecnología, BR).

El análisis consistió en la comparación de los patrones obtenidos para cada muestra con los controles utilizados. Se analizaron las bandas presentes y ausentes en cada especie, tanto a través de la observación de la corrida electroforética, como de un diagrama en que se reprodujeron las bandas aparecidas en ésta.

Consideraciones éticas: Las muestras de los órganos de perros, tanto ganglio linfático poplíteo y bazo, que se utilizaron en este estudio, fueron obtenidas a partir de animales con serología positiva para la leishmaniasis visceral, luego de la eutanasia humanitaria realizada con el consentimiento previo de sus dueños quienes firmaron un acta para llevar a cabo el procedimiento, teniendo en cuenta las normas previstas por el Programa Nacional de Control de Zoonosis y Centro Antirrábico Nacional del Ministerio de Salud Pública y Bienestar Social. Previamente al sacrifico, el personal del Ministerio consideró las precauciones necesarias para evitar sufrimientos innecesarios a los animales, según los principios Internacionales de Guías de la Investigación Biomédica que utiliza animales, elaborados por el consejo de Organizaciones Internacionales de Ciencias Médicas (CIOMS) y el Consejo Internacional de Ciencia y Animales de Laboratorio (ICLAS), además se tuvo en cuenta lo dispuesto en la Ley 4840/2013 sobre protección y bienestar animal dictada por el Poder Legislativo Nacional (22-24).

\section{RESULTADOS}

\section{ITS1-PCR a partir de ADN de parásitos en medio de cultivo bifásico NNN:}

Para la amplificación de la región ITS1 de parásitos aislados en medio de cultivo, se detectó el blanco molecular con $5 \mu \mathrm{L}$ de ADN a concentración de $3 \mathrm{ng} / \mu \mathrm{L}$, por lo que fue suficiente para observar bandas nítidas. En estas reacciones además fueron testadas concentraciones de $8,15,31$ y $51 \mathrm{ng} / \mu \mathrm{L}$ del ADN, en las cuales de manera similar se observaron bandas bien diferenciadas con los productos de 300-350 pb en los 10/10 aislados de parásitos que reunían las condiciones del criterio de inclusión del trabajo. La amplificación obtenida se visualiza en la Figura 1. 


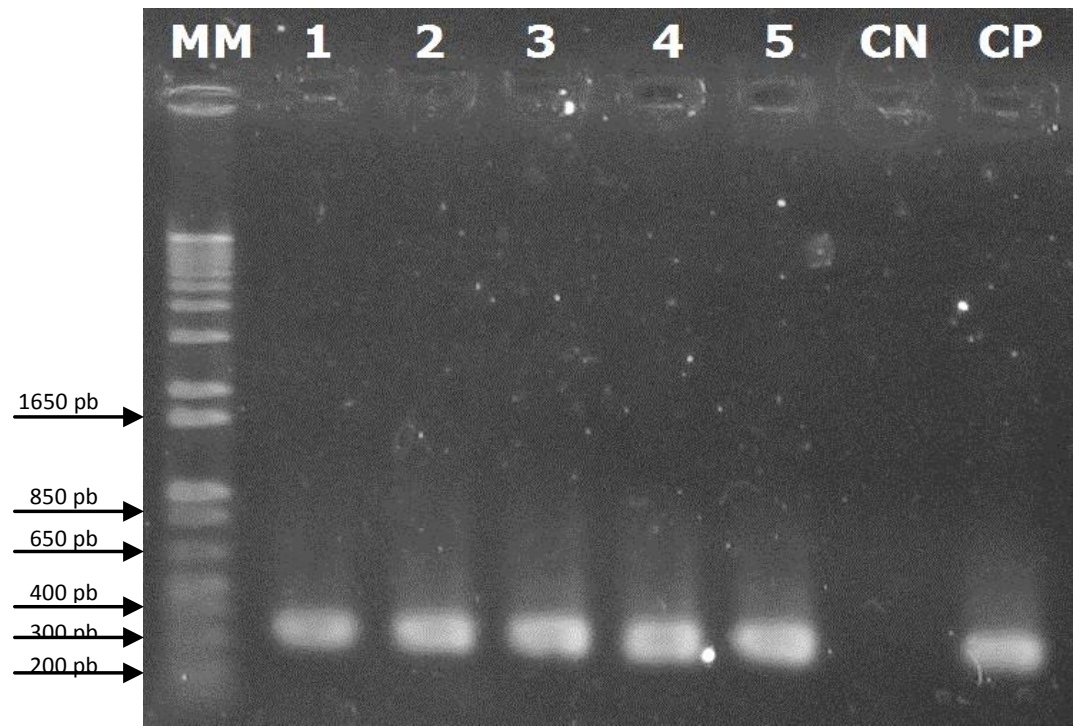

Figura 1. Electroforesis en gel de agarosa al $1 \%$ con los productos obtenidos por la amplificación de la región ITS1 con los cebadores LITSR y L5,8S. MM: Marcador de peso molecular de 1 kb (Invitrogen, EEUU). Carriles 1 al 5, muestras de parásitos aislados en medio de cultivo NNN. CN: Control negativo. CP: Control positivo - Leishmania (L.) infantum (MHOM/FR/78/LEM75).

\section{ITS1-PCR a partir de ADN de parásitos en muestras de biopsias:}

Para la amplificación de la región ITS1 de parásitos en ganglio linfático poplíteo, las concentraciones menores a $60 \mathrm{ng} / \mu \mathrm{L}$ no fueron suficientes para detectar el blanco molecular, a pesar de la realización de varias reacciones de amplificación sólo se lograron amplificar 10 de las 18 muestras. La sensibilidad de la técnica para este blanco se determinó en una concentración de $60 \mathrm{ng} / \mu \mathrm{L}$ utilizando $5 \mu \mathrm{L}$ del ADN en la mezcla final de reactivos de la PCR. Esta concentración permitió la observación de bandas nítidas con los productos de 300-350 pb (Figura 2). Los perfiles de bandas obtenidos con el blanco de ADN (ITS1) de los parásitos encontrados en el bazo, también fueron visualizados de forma nítida con la misma concentración utilizada a partir del ADN de los parásitos en ganglio linfático (60 $\mathrm{ng} / \mu \mathrm{L})$, en la que se logró amplificar 10 de las 18 muestras. Esto se muestra en la Figura 2.

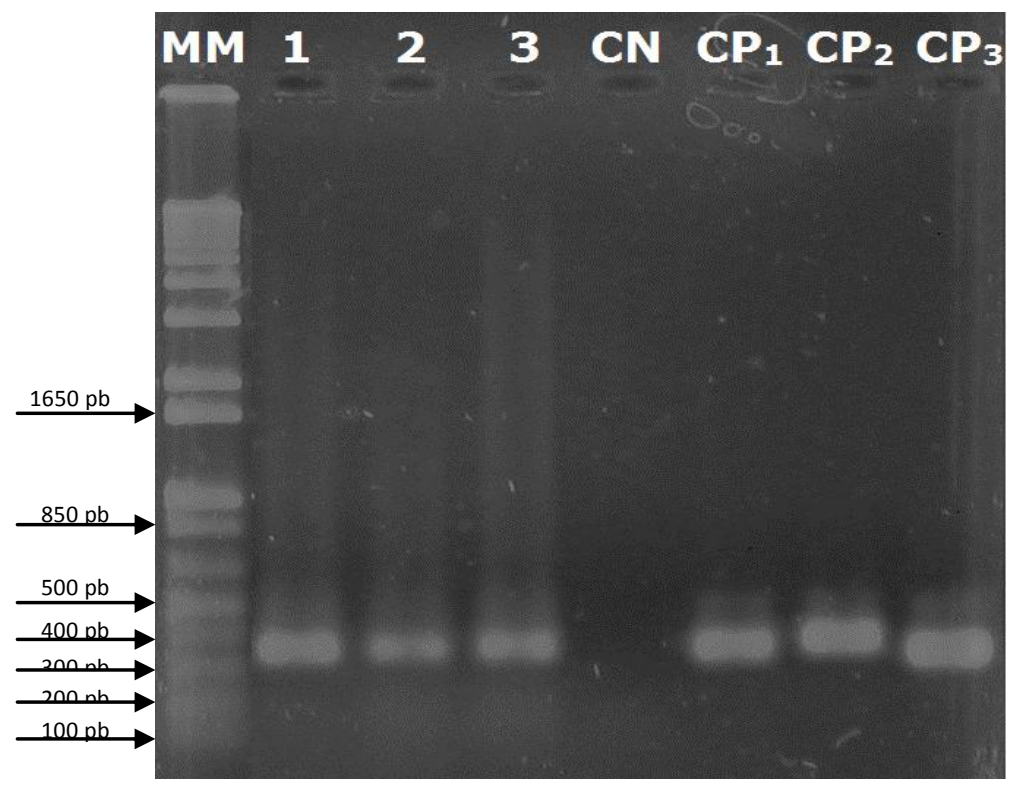

Figura 2. Electroforesis en gel de agarosa al $1 \%$ con los productos obtenidos por la amplificación de la región ITS1 con los cebadores LITSR y L5,8S. MM: Marcador de peso molecular de 1 kb (Invitrogen, EEUU). Carriles 1 y 3: muestra de parásitos aislados de biopsias (bazo). Carril 2: muestra de parásitos aislados de biopsias (ganglio linfático poplíteo). $\mathrm{CN}$ : Control negativo. $\mathrm{CP}_{1}$ : Control positivo Leishmania (L.) infantum (MHOM/FR/78/LEM75). $\mathrm{CP}_{2}$ : Control positivo Leishmania (L.) amazonensis (MHOM/BR/73/M2269). $\mathrm{CP}_{3}$ : Control positivo Leishmania (V.) braziliensis (MHOM/BR/75/M2903). 


\section{Análisis de la longitud de los fragmentos de restricción del producto amplificado (PCR-RFLP)}

La digestión enzimática fue desarrollada con $10 \mu \mathrm{L}$ del producto de la PCR mezclado con $17 \mu \mathrm{L}$ de agua ultra pura y mezcla de reacción para restricción enzimática, que contenía la enzima y el buffer proveído por el fabricante (Invitrogen, EEUU). La visualización del perfil en geles de agarosa comparado con un marcador de tamaño molecular permitió observar fragmentos resultantes del corte enzimático. Sin embargo, los resultados obtenidos son aún preliminares, considerando que será necesario ajustar la nitidez de las bandas con tamaños menores a $100 \mathrm{pb}$, ya que a partir del producto amplificado de 300-350 pb se espera que la endonucleasa Hae III resulte en fragmentos de 184, 72 y 55 pares de bases, correspondiente a la especie Leishmania (L.) infantum. Nuestro resultado permitió la observación del fragmento de mayor tamaño, mientras que los dos fragmentos menores se observaron de manera difusa, sin embargo, se observó que la enzima realiza tales cortes, lo que pudo verificarse con los controles positivos utilizados.

Con el fin de facilitar el análisis del patrón de bandas obtenido, en la fotografía correspondiente al gel de RFLP (Figura 3), se muestra una representación esquemática del mismo en la Figura 4.

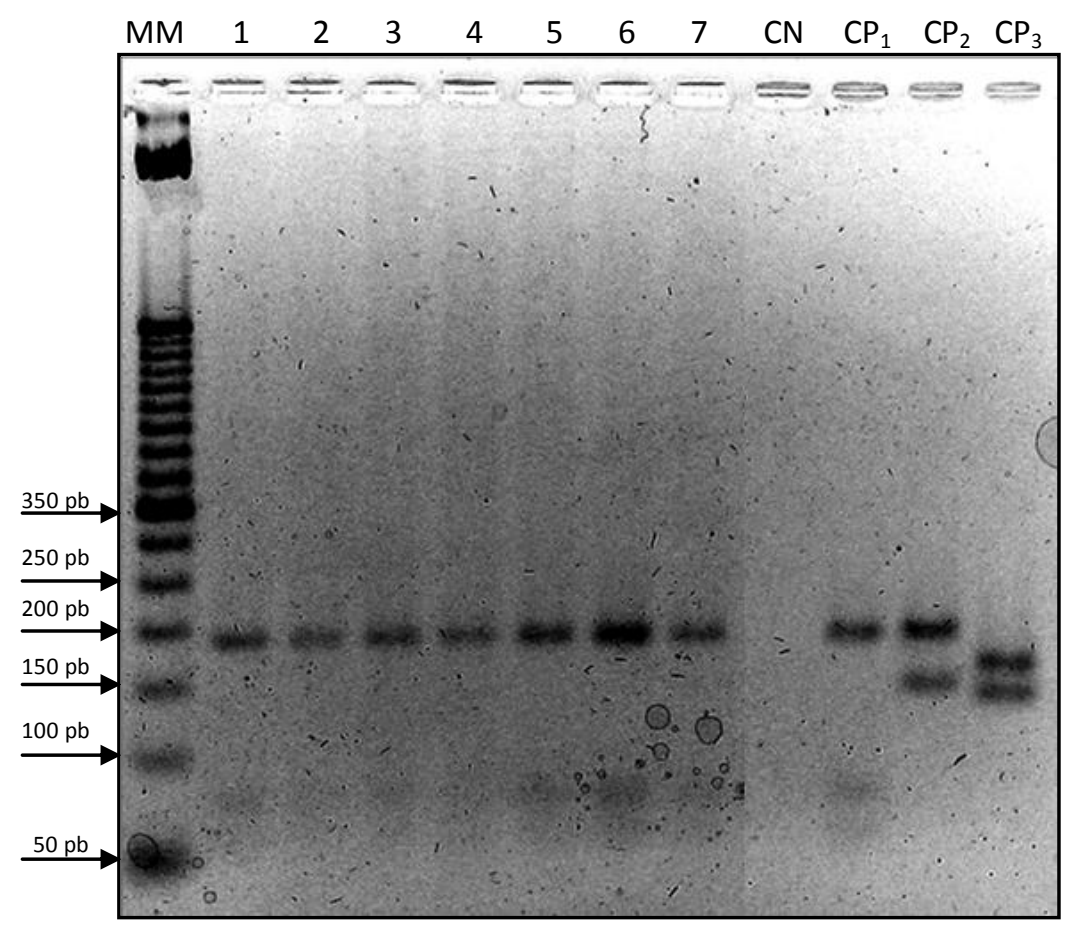

Figura 3. Electroforesis en gel de agarosa al $3 \%$. Patrones de bandas obtenidos, a partir de la digestión del producto de ITS1-PCR con la enzima de restricción Hae III. MM: Marcador de peso molecular de $50 \mathrm{pb}$ (Invitrogen, EEUU). Carriles 1 al 7: muestra de parásitos aislados en medio de cultivo bifásico NNN. CN: Control negativo. $\mathrm{CP}_{1}$ : Control positivo Leishmania (L.) infantum (MHOM/FR/78/LEM75). CP : Control positivo Leishmania (L.) amazonensis (MHOM/BR/73/M2269). $\mathrm{CP}_{3}$ : Control positivo Leishmania (V.) braziliensis (MHOM/BR/75/M2903). 


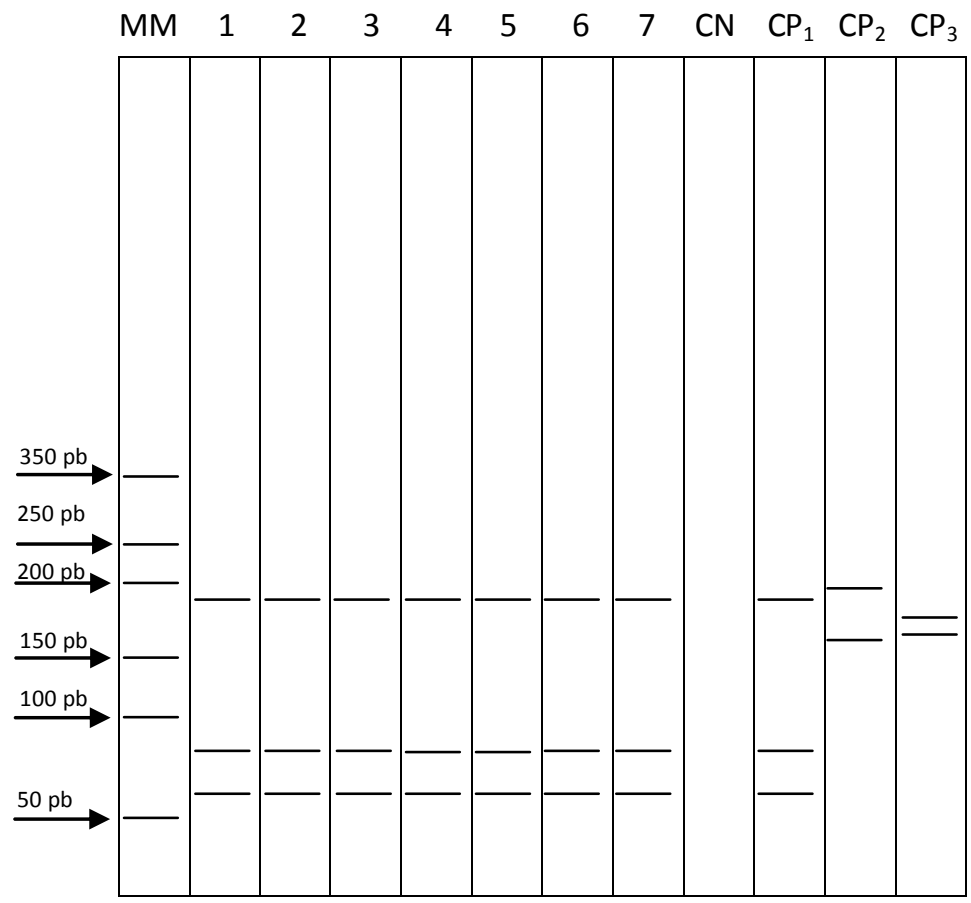

Figura 4. Diagrama en el que se reproducen los fragmentos observados en el gel de agarosa al $3 \%$ con los patrones de bandas obtenidos en la figura 3.

\section{Comparación de la amplificación por PCR obtenida a partir del ADN de parásitos aislados de cultivo y muestras de biopsias.}

En la tabla se muestra un resumen de las amplificaciones obtenidas para cada grupo de muestras procesadas. Los resultados muestran, como era de esperarse, que la sensibilidad de la PCR es mayor cuando se trata de amplificar el ADN a partir de muestras de cultivo (estadío promastigote), en este caso en el $100 \%$ de las muestras se detectó la presencia del género Leishmania sp. con la amplificación del ITS1. Con las muestras obtenidas a partir de muestras de biopsias (bazo y ganglio linfático), la PCR ha demostrado ser menos sensible (Tabla 1).

Tabla 1. Porcentajes de amplificación lograda para la PCR-ITS1 a partir de aislados en medio de cultivo y muestras de biopsias (resultados preliminares).

\begin{tabular}{llll}
\hline Muestras & Total & PCR positivo & PCR positivo (\%) \\
\hline Cultivo & 10 & 10 & 100 \\
Bazo & 18 & 10 & 55,56 \\
Ganglio linfático poplíteo & 18 & 10 & 55,56 \\
Total & 46 & 30 & 65,21 \\
\hline
\end{tabular}

\section{DISCUSIÓN}

Desde el punto de vista epidemiológico, la caracterización de parásitos de Leishmania a nivel de subgénero y especie es importante para establecer la precisa distribución geográfica y el modo de transmisión de éstos patógenos hacia los humanos, así como para establecer el diagnóstico clínico y la evaluación de esquemas terapéuticos adecuados para la enfermedad (25). Está demostrado que la leishmaniasis visceral es producida por $L$. infantum y es endémica en nuestro país, especialmente en Asunción, departamentos Central y Cordillera, en donde se ha observado una elevada seroprevalencia en el reservorio principal, el perro doméstico (26). Con la utilización de diversas herramientas moleculares han sido observados altos niveles de variación inter e intra especies tanto en el Viejo como en el Nuevo Mundo. En la actualidad se utilizan técnicas moleculares tales como, la secuenciación, RAPD (Random Amplified Polymorphic DNA), IRT (Intergenic Ribosomal Typing), entre otras (27). Diferentes blancos de amplificación han sido utilizados, pero los que presentan mayor sensibilidad son los que se encuentran en secuencias multicopias, como el gen de la subunidad pequeña ribosomal (SSU rRNA), secuencias repetitivas del Mem. Inst. Investig. Cienc. Salud. 2016;14(3):24-33 
ADN genómico o de los minicírculos del ADN del kinetoplasto (kDNA), el gen del locus gp63, los cuales han sido utilizados no sólo para la detección sino para la identificación de los parásitos (27). El uso de la Reacción en Cadena de la Polimerasa, unido a la técnica de Polimorfismo en la longitud de los fragmentos de restricción (PCR-RFLP) también se ha utilizado con el propósito de identificación y caracterización de Leishmania (28). El método de amplificación de la región ITS1 seguido del método de RFLP proporciona alta sensibilidad en el diagnóstico e identificación utilizando diferentes tipos de muestras, tal como se ha verificado en este trabajo. Por otra parte, este método puede constituir una herramienta útil para lograr la diferenciación de especies mediante la digestión con endonucleasas de restricción. Así la técnica permite la diferenciación entre las diversas especies (29).

En nuestro país se han registrado estudios previos acerca de la caracterización molecular de Leishmania, utilizando marcadores tales como kDNA, SLME, Hsp70, entre otros (30-33).

La amplificación de la región ITS1 lograda en nuestro estudio, permitió la identificación de bandas nítidas pertenecientes a Leishmania sp., principalmente cuando fueron amplificados los fragmentos de ADN extraídos de muestras derivadas de cultivos, que a pesar de generar una buena cantidad de producto presentó diferencia en comparación a la amplificación obtenida a partir del ADN derivado de las biopsias. Esto concuerda con lo observado por algunos autores que reportaron diferencias en la carga parasitaria y cantidad de ADN, según la(s) especies de Leishmania que estarían parasitando al animal, así como se han observado diferencias entre órganos de un mismo huésped. Esto como consecuencia afecta la sensibilidad de las técnicas moleculares, por lo que pudiese tener menor número de copias de alguna diana para determinadas especies y localizaciones del parásito dentro de su huésped (20), lo que nos lleva a pensar que una óptima concentración de reactivos de PCR podría ser determinante para la detección de algunas especies en particular. Nuestros resultados permitieron observar cómo la concentración de 0,2 mM de dNTPs, 1,5 mM de $\mathrm{MgCl}_{2}$ y 0,1 pmol de cada cebador fue óptima para amplificar la región en cuestión.

Por otra parte, los cortes en fragmentos de los productos amplificados que permiten observar diferencias en la longitud de estos fragmentos de restricción y por ende diferencias entre especies a través de la técnica de la PCR-RFLP de la región ITS1, en nuestro estudio sólo se logró detectar parte de los fragmentos que correspondería a la especie Leishmania infantum, es decir, que la técnica aún no permitió detectar con claridad y nitidez los dos fragmentos de menor tamaño, por lo que será necesario continuar las pruebas relacionadas a la caracterización de especies de Leishmania. Sin embargo, a pesar de lo mencionado, se observó mayor similitud de los cortes procedentes de las muestras caninas, comparadas con los fragmentos de la cepa de referencia internacional MHOM/FR/78/LEM75 perteneciente a Leishmania infantum, utilizada como control positivo.

Esta técnica constituye una herramienta valiosa para el diagnóstico molecular de la leishmaniasis en sus diversas manifestaciones clínicas (LV, LC, LMC) (34) directamente en muestras biológicas o en aislados de medio de cultivo, como así también para el control de la calidad (pureza) de cepas de referencia internacional mantenidas en laboratorios. Similarmente, la PCR constituye una herramienta muy útil para el diagnóstico de la leishmaniasis canina y la implicación de los caninos como reservorios en las distintas zonas endémicas para la LV, siendo de gran importancia para la detección de casos asintomáticos. A pesar de esta afirmación, se debe enfatizar que no siempre la técnica de PCR muestra mejores índices diagnósticos que las técnicas convencionales (35), por lo que es recomendable su uso en conjunto con otras técnicas para lograr un diagnóstico certero de leishmaniasis y así, basados en esto, fortalecer los programas de control vigente en nuestro país (36).

El ensayo de PCR-RFLP es considerado una de las herramientas multipropósito para el diagnóstico directo de muestras clínicas, incluso sin aislamiento previo del parásito; por lo que es recomendado para la caracterización de especies del género Leishmania en zonas endémicas donde circulan varias especies, y por ende exigen una identificación a bajo costo. Este trabajo sugiere continuar con las pruebas realizando algunas modificaciones adecuadas a las condiciones de laboratorio, considerando que, un principio fundamental para el uso de la PCR continúa siendo su optimización, con el fin de garantizar una amplificación exitosa (35). Finalmente, esta técnica estandarizada será muy valiosa en el diseño e implementación de sistemas de control y vigilancia de las leishmaniasis. 


\section{AGRADECIMIENTOS:}

Al Dr. Jorge Miret, del PNCZ y CAN por el diagnóstico clínico y la toma de muestras de los caninos. A los estudiantes de veterinaria Gustavo Dávalos, Lidia Boy y Victor Agüero por su valiosa e incansable colaboración en la colecta de muestras así como a los técnicos del PNCZ y CAN del Ministerio de Salud.

Financiamiento: IDRC (International Development Research Centre), financiamiento parcial obtenido en el marco del Proyecto Abordando la Emergencia y Dispersión de la Leishmaniasis en las Fronteras Argentina, Brasil y Paraguay. Proyecto Nro. 107577-003.

\section{REFERENCIAS BIBLIOGRÁFICAS}

1. Atias A. Parasitología Médica. $1^{a}$ ed. Santiago, Chile: Mediterráneo; 1998.

2. Ashforf RW. The leishmaniases as emerging and reemerging zoonoses. Int. J. Parasitol. 2000; 30(12-13): 1269-81.

3. Desjeux P. Leishmaniasis: current situation and new perspectives. Comp. Immunol. Microbiol. Infect. Dis. 2004; 27(5): 305-18.

4. WHO. World Health Organization Leishmaniasis. 2015; Fact sheet $N^{\circ} 375$.

5. Dantas - Torres F. Canine leishmaniosis in South America. Parasit Vectors. 2009; 2.

6. Dias ES, Regina-Silva S, França-Silva JC, Paz GF, Michalsky EM, Araujo SC, et al. Ecoepidemiology of visceral leishmaniasis in the urban area of Paracatu, state of Minas Gerais, Brazil. Vet. Parasitol. 2011; 176 (23):101-11.

7. Chance ML, Walton BC. Biochemical characterization of Leishmania. Chance ML, Walton BC, eds. Geneva: UNDP/ World Bank/WHO; 1982: 1-275.

8. Gramiccia M, Smith DF, Angelici MC, Raedy PD, Gradoni L.A kinetoplast DNA probe diagnostic for $L$. infantum. Parasitology 1992; 105:29-34.

9. Giuziani I, Dellagi K, Isamail RB. Random amplified polymorphic DNA technique for identification and differentiation of Old World Leishmania species. Am J Trop. Med Hyg 2002; 66:152-6.

10. Tybairenc M, Neubauer K, Barnabe C, Guerrini F, Skareckey D, Ayala FJ. Genetic characterization of six parasitic protozoa parity between random primer DNA typing and multilocus enzyme electrophoresis. Proc Nat Acad Sci USA 1993; 90: 1335-9.

11. Dujardin JC, Gajendran N, Arevalo J, Llanos Cuentas A, Guerra H, Gomez J, et al. Karyotype polimorphism and conserved characters in the Leishmania (Viannia) braziliensis complex explored with chromosome derived probes. Ann Soc Belge Med Trop 1993; 73: 101-18.

12. Marfurt J, Nasereddin A, Niederwieser I, Jaffe CL, Beck HP, Felger I. Identification and diferentiation of Leishmania species in clinical samples by PCR amplification of the miniexon sequence and subsequent restriction fragment length polymorphism analysis. J Clin Microbiol. 2003; 41: 314753.

Mem. Inst. Investig. Cienc. Salud. 2016;14(3):24-33
13. García AL, Kindt A, Quispe Tintaya WQ, Bermúdez $H$, Llanos $A$, Arévalo $J$, et al. American tegumentary leishmaniasis antigen gene polymorphism, taxonomy and clinical pleomorphism. Infect Genet Evol 2005; 5: 109-16.

14. Orué A. Marcadores moleculares en Kinetoplastida: Secuencias diagnósticas de DNA nuclear de los subgéneros Viannia y Leishmania y el desarrollo de un ensayo múltiple de PCR (Multiplex PCR) en la identificación del parásito. Memorias del Instituto de Biología Experimental. 2005; 4:121-124.

15. De Santis B, Santos E G, Oliveira B, Cupolillo E, Porrozzi R, Cavalcanti A, Santos B. et al. Characterization of Leishmania infantum species in dogs from the urban area of Cuiabá, State of Mato Grosso, Brazil. Rev. Soc. Bras. Med. Trop. [serial on the Internet]. $2011 \mathrm{Dec}$; 44(6): 771-773.

16. Arleana do Bom Parto Ferreira de Almeida, Valéria Régia Franco Sousa, Eveline da Cruz Boa Sorte, Fabiano Borges Figueiredo, Daphine Ariadne Jesus de Paula. et al. Use of Parasitological Culture to Detect Leishmania (Leishmania) chagasi in Naturally Infected Dogs. Vector-Borne and Zoonotic Diseases. December 2011, 11(12): 1555-1560. doi:10.1089/vbz.2011.0723.

17. Sambrook J, Fritsch E, Maniatis T. Molecular cloning. a laboratory manual. New York : Cold Spring Harbor Laboratory Press; 1989.

18. Meredith SEO, Zijlstra EE, Schoone GJ, Kroon CCM, Van Eys GJ, Schaeffer KU, El Hassan AM, Lawyer PG. Development and application of the polymerase chain reaction for the detection and identification of Leishmania parasites in clinical material. Archives Institute Pasteur Tunis. 1993; 70: 419-431.

19. Sambrook J, Russell D., Molecular Cloning. A Laboratory Manual, 3ra Ed., Cold Spring Harbor Laboratory Press. New Cork .2001; p:6.3-6.30.

20. Schönian G, Nasereddin A, Dinse $N$, Schweynoch C, Schallig HDF, Presber W, Jaffe CL. PCR diagnosis and characterization of Leishmania in local and imported clinical samples. Diagn. Microbiol. Infec. Dis. 2003; 47, 349-358.

21. Kuhls, K, I. L. Mauricio, F. Pratlong, W. Presber and G. Schonian. Analysis of 
ribosomal DNA internal transcribed spacer sequences of the Leishmania donovani complex. Microbes Infect. 2005; 7 (11-12): 1224-34.

22. Council for International Organizations of Medical Sciences (CIOMS). Pautas éticas internacionales para la investigación biomédica en seres humanos. Ginebra 2002. Disponible www.cioms.ch/1985_texts_of_guidelines.htl $\mathrm{m}$

23. International Council for Laboratory Animal Science. International Guiding Principles for biomedical Research involving animals. December 2012. Disponible en: http://iclas.org/wpcontent/uploads/2013/03/CIOMS-ICLASPrinciplesFinal.pdf

24. Congreso de la Nación Paraguaya. Ley 4840/2013 de Protección y Bienestar Animal. Biblioteca y Archivo Central del Congreso Nacional. 2013. Disponible en: http://www.bacn.gov.py/OTU0\&ley-n-4840

25. Mendoza León, A; Shaw, J; Tapia, F. A guide for the Cutaneous Leishmaniasis Connoisseur. Molecular and Inmune mechanisms in the pathogenesis of Cutaneous leishmaniasis. Londres Company. 1996; cap 1, pp: 1-22.

26. Canese Krivoshein AP, Morel Ayala ZR, Martínez Gamba JD, Tonina SENES AJ, Torres Heisecke $\mathrm{R}$, et al. Prevalencia de leishmaniasis visceral Humana y canina en la ciudad de Lambaré, Paraguay; Humana and canine visceral leishmaniasis in Lambaré city, Paraguay. An. Fac. Cienc. Méd. Asunción. 1999;32(1/2):42-74.

27. Marfurt J, Niederwieser I, Makia ND, Beck H, Felger I. Diagnostic genotyping of Old and new world Leishmania species by PCR-RFLP. Diagn Microbiol Infect Dis 2003; 46(2):11524.

28. Cupolillo E, Grimaldi G, Momen H, Beverley SM. Intergenic region typing (IRT): a rapid molecular approach to the characterization and evolution of Leishmania. Mol. Biochem. Parasitol. 1995; 73: 145-55.

29. Miranda H, Alfaro A, Lora C, Rodríguez L. Estudio comparado de métodos de diagnóstico de la leishmaniasis y caracterización molecular de los agentes etiológicos en la Libertad. Folia Dermatol. 2003; 14 (2): 18-23.

30. Chena L, Nara E, Canese A, Oddone R, Morán M, Russomando G. Caracterización de cepas de Leishmania, por medio de la técnica de PCR-RFLP de la región del Spliced Leader Miniexon (SLME), aisladas de humanos y caninos en Paraguay. Mem. Inst. Investig. Cienc. Salud, Vol. 10(1) Junio 2012: 14-23.
31. Chena L, Nara E, Canese AIII, Oddone R, Russomando G Aplicación de la PCR para la detección de género y complejos de Leishmania en diferentes tipos de muestras biológicas. Mem. Inst. Investig. Cienc. Salud, Vol. 9(1) Junio 2013: 45-5.1.

32. Gómez de la Fuente, A S. Análisis de la diversidad genética de Leishmania infantum en Paraguay, mediante la técnica KDNAPCR.RFLP. Tesis de Maestría. Instituto de Investigaciones en Ciencias de la Salud. Paraguay, 2013.

33. Portillo, N. González Brítez, N. Caracterización molecular de parásitos aislados de perros diagnosticados con leishmaniosis visceral en el Centro Antirrábico Nacional (CAN) de Paraguay años 2012- 2013. Revista Investigaciones y Estudios de la UNA. 2013. ISSN/ISBN 2070/0415. Disponible en http://sdi.cnc.una.py/catbib/documentos/65 7.pdf

34. Monroy-Ostria, Amalia, Victor $M$ Monteon, Carmen Guzmán-Bracho,Charles L Jaffe. ITS1 PCR-RFLP Diagnosis and Characterization of Leishmania in Clinical Samples and Strains from Cases of Human Cutaneous Leishmaniasis in States of the Mexican Southeast. 2014 Jul 1. Hindawi Publishing Corporation Interdisciplinary Perspectives on Infectious Diseases Volume 2014, Article ID 607287.

35. Ferrer E., Lares M., Viettri M. Comparación entre Técnicas inmunológicas y moleculares para el Diagnóstico de la Enfermedad de Chagas. Enferm Infecc Microbiol Clin. 2013; 31(5): 277-82.

36. Amini B, Olyaee S, Sahabi F, Karimi M. PCR Optimization improving of human cytomegalovirus (HCMV) PCR to achieve a highly sensitivity detection method. Iranian J. Biotechnol 2003; 1:59-64. 